\title{
Investigation into the Negative Effects of Energy Drinks on Liver Efficiency and Lipid Metabolism in Rats
}

\author{
Mohannad A. Alsiddiqi ${ }^{1}$, Fares K. Khalifa ${ }^{2}$ and Othman A. Baothman ${ }^{3}$ \\ ${ }^{1}$ Department of Biochemistry, Faculty of Science, King Abdulaziz University, Jeddah, Saudi Arabia \\ ${ }^{2}$ Department of Biochemistry, Faculty of Science, King Abdulaziz University, Jeddah, Saudi Arabia \\ ${ }^{3}$ Microbial Toxicology \& Natural Products Center, Faculty of Science, King Abdulaziz University, \\ Jeddah, Saudi Arabia
}

\section{ABSTRACT}

This study aims to evaluate the negative effects of consumption of two types of Energy drinks; Red Bull (RB) and Code Red (CR) at two levels of doses on liver functions and lipid metabolism in rats.Fourty male adult albino rats (weighing 80-100 g) were randomly assigned to five groups (8 rats per group) each was orally administered. Group 1 (control group), Group 2 and 3 received low doses of RBand CR (each 5ml/day per kg b.w), respectively, Group 4 and 5 received high doses of RB and CR (each $10 \mathrm{ml} /$ day per kg b.w), respectively. At the end of the 31st day of experiment, liver functions and lipid profile were investigatedData revealed that energy drinks affected the liver enzymes activities (ALT, AST, and ALP). Also changed in serum total proteins and albumin which were highly significantly $(\mathrm{P} \leq 0.05)$ affected at high doses of both energy. The results of total lipids, total cholesterol, triacylglycerols and LDL-cholesterol showed a significant lower levels of co administered lower or higher doses of RB or CR(5ml/day or $10 \mathrm{ml} /$ day respectively), while the activity of serum FAS and ACC were significantly $(\mathrm{P} \leq 0.05)$ higher in rats administered high doses of both energy drinks. Also, the values of serum glucose and insulin were significantly $(\mathrm{P} \leq 0.05)$ higher in rats administered high doses of both energy drinks. These data emphasize that high doses of energy drinks were clearly effective of liver enzymes, glucose and fat metabolism.

KEY WORDS: CAFFEINE, ENERGY DRINKS, LIVER TOXICITY, RED BULL, TAURINE.

\section{INTRODUCTION}

(Alford et al., 2001)define energy drinks (EDs) are carbonated refreshments containing high concentrations of metabolic energizers. These drinks are said to enhance energy, readiness and perseverance, which has caused

\section{ARTICLE INFORMATION}

Received 17th Oct 2020 Accepted after revision 15th Dec 2020 Print ISSN: 0974-6455 Online ISSN: 2321-4007 CODEN: BBRCBA

Thomson Reuters ISI Web of Science Clarivate Analytics USA and Crossref Indexed Journal

\section{Clarivate
Analytics}

NAAS Journal Score 2020 (4.31)

A Society of Science and Nature Publication,

Bhopal India 2020. All rights reserved.

Online Contents Available at: http//www.bbrc.in/

Doi: $h$ ttp://dx.doi.org/10.21786/bbrc/13.15/22 drastic increases in their popularity over the last few years (Seifert et al., 2011). Several studies have found that Eds have transitory medical benefits, including the capacity the enhance sharpness, endurance and to conquer exhaustion in young people and adults (Howard and Marczinski, 2010). For example, (Souza et al., 2017) found that ED consumption improves perseverance, muscular strength and performance in sports activities. On the other hand, some researchers (Elitok et al., 2016, González Domínguez et al., 2017, Grasser et al., 2014, Higgins et al., 2015, Monnard et al., 2016, Nowak et al., 2018, Al Yacoub et al., 2020) have found that both short and long-term consumption of these drinks can have negative effects on the body. Such effects include poor heart rate, type 2 diabetes, cardiovascular disease, obesity and hypertension. 
Moreover, a case study found that ED may be related to kidney disease and hepatitis. In 2014, the World Health Organization (WHO) stated that energy drinks can have significant negative effects on adults and may cause lasting damage. However, following the regulations implemented on alcohol and tobacco sales in the same year, the ED market has experienced significant growth, with many different brands being created across the globe. (Bailey et al., 2014)report that approximately 5.8 billion litres of energy drinks were sold in 2013 across 160 countries. Caffeine (1,3,7-trimethylxanthine), is the primary ingredient in EDs contain approximately80$150 \mathrm{mg}$ of caffeine in 8 ounces and actively stimulates the cardiovascular and central nervous systems (Boeck et al., 2009, Glade, 2010, Wolk et al., 2012).

A majority of these drinks contain high levels of glucose, and some companies have even offered misleadingly improved adaptations. Taurine is also a widely-used ingredient in such drinks, (2-aminoethanesulfonic acid), which is the most abundant form of amino acid which is either obtained through one's diet or synthesized from cysteine in the liver. Moreover, it plays a fundamental role in numerous bodily systems, including the central nervous system and also serves as an antioxidant, neurotransmitter and membrane stabilizer (Vivekanandarajah et al., 2011, Caine and Geracioti, 2016). Energy drinks may also contain a variety of other ingredients, including ginseng, methylxanthines, yerba mate, guarana, acai, maltodextrin, creatine, inositol, carnitine, glucuronolactone, and ginkgo biloba extract. However, there are major concerns surrounding the safety of energy drinks sold on the market.

The present research thus aims to assess the negative impacts that two types of energy drinks have on liver function and lipid metabolism, namely Red Bull and Code Red. The study will be performed using male albino rats and is inspired by the apparent attractiveness of such drinks and concern regarding the unknown toxicological effects of their excessive consumption.

\section{MATERIAL AND METHODS}

Materials: All reagents used in this study were of analytical grade and were purchased from Siemens Healthcare Diagnostics and Bioassay technology laboratory. The energy drinks (Red Bull and Code Red) was purchased from local markets.

Experimental Animals: The adult male albino rats each weighing 80-100 g (eight per each group) were used in this study and supplied from the Animal House Colony of King Fahd Medical Research Center, Jeddah and acclimatized with a $12 \mathrm{~h}$ light/dark cycle at King Fahd Medical Research Center Animal Facility Breeding Colony. Rats were housed with ad libitum access of water and standard laboratory diet. The experiment was conducted in accordance with ethical guidelines of the Animal Care and Use Committee of King Abdulaziz University.
Experimental Design: Forty male rats were randomly divided to five groups (8 rats per group). The groups were treated as follows:

Group 1 (Control): received distilled water by oral gavage

Group 2 (RB-LD): Rats were administrated Red Bull, low dose ( $5 \mathrm{ml} /$ day) by oral gavage.

Group 3 (CR-LD): Rats were administrated Code Red, low dose ( $5 \mathrm{ml} /$ day) by oral gavage.

Group 4 (RB-HD): Rats were administrated Red Bull, high dose (10 ml/day) by oral gavage.

Group 5 (CR-HD): Rats were administrated Code Red, high dose (10 ml/day) by oral gavage.

The total duration of the experiment was 31 days. The body weights of rats were measured at the beginning and at the end of experiment. At the end of four weeks (experimental period), the animals were starved for 12 hours prior to blood collection. Rats were sacrificed under ether anesthesia, then blood was collected through optic nerve puncture. Serum was separated by allowing blood samples left for 30 minutes at temperature of $25^{\circ} \mathrm{C}$ then centrifuged at 3000 r.p.m for 10 minutes, then divided into several aliquots and stored at $-20 \mathrm{C}$ until analysis was performed.

Biochemical Assays: Sera of the studied rats were collected and the levels of ALT, AST, ALP, T \& D. Bilirubin, T. Protein, Albumin, T lipid, Cholesterol, Triglycerides, LDL, HDL and glucose were measured using Dimension VISTA 1500 (SIEMENS).

FAS, ACC and insulin were measured by double-antibody sandwich enzyme-linked immunosorbent assay (ELISA) (Bioassay Technology Laboratory).

Statistical Analysis: Analyzing thedata were conducted by statistical package software (SPSS). The t-test of significance was tested for identified the differences between the means. Results were expressed as mean \pm SEM.

\section{RESULTS}

Effect of EDS on Body Weight: Results outlined in Table 1 uncover that EDs had more impact on body weight gain, with $89.66 \%$ and 84.67 \%for high doses Red Bull and Code Red compared with control (61.55 \%),respectively. Changes in body weight were significantly $(P \leq 0.05)$ more influenced of higher doses of EDs than lower doses of both EDs (RB-LD and CR-LD).

Effect of EDS on Serum Levels of Liver Enzymes and Lipid Profile: Figure 1represent the impact of EDs on liver function enzymes (ALT, AST, and ALP).Generally, higher ALT was recorded in experimental ratswhen compared with the control, with essentially more elevated levels of ALP and AST exerted in rats co-administered both lower and higher doses of RB and CR. Utilization of EDs has higher impact on serum total protein and albuminlevels particularly at higher doses of energy drinks as compared 
with control group(Figure 2). However, lower levels of bilirubin and direct bilirubin were recorded in animals administered low and high doses of EDs comparable to the control group (Figure 3).

\begin{tabular}{|c|c|c|c|c|}
\hline $\begin{array}{l}\text { Change in } \\
\text { body weight }\end{array}$ & $\begin{array}{l}\text { Weight Gain } \\
\qquad(\%)\end{array}$ & $\begin{array}{c}\text { Final Weight } \\
(\mathrm{g})\end{array}$ & $\begin{array}{l}\text { Initial Weight } \\
\text { (g) }\end{array}$ & $\begin{array}{l}\text { Groups } \\
\text { (g) }\end{array}$ \\
\hline 61.55 & 60.96 & $160 \pm 12.23$ & $99.04 \pm 9.93$ & G1 (control) \\
\hline 53.77 & 55.25 & $158 \pm 25.95$ & $102.75 \pm 9.33$ & G2 (RB-LD) \\
\hline 66.48 & 75.13 & $188.125 \pm 27.16^{* * *}$ & $113 \pm 11.11$ & G3 (CR-LD) \\
\hline 89.66 & 90.00 & $190.375 \pm 13.33^{* * *}$ & $100.37 \pm 19.11$ & G4 (RB-HD) \\
\hline 84.67 & 82.87 & $180.75 \pm 18.56^{* *}$ & $97.88 \pm 10.27$ & G5 (CR-HD) \\
\hline \multicolumn{5}{|c|}{$\begin{array}{l}\text { All statistics data were stated as mean } \pm \text { SEM using student t-test with significant } \\
\text { differences at } p<0.05, p<0.001 \text { and } p<0.0001 \text { as indicated by }\left(^{*}\right),\left({ }^{* *}\right) \mathrm{Ct}\left({ }^{* * *}\right) \text { compared } \\
\text { to normal control }(\mathrm{G} 1) \text {, respectively. RB-LD }=5 \mathrm{ml} \text { Red Bull/day; CR-LD }=5 \mathrm{ml} \text { Code } \\
\text { Red/day; RB-HD=10 ml Red Bull/day; CR-HD }=10 \mathrm{ml} \text { Code Red/day. }\end{array}$} \\
\hline
\end{tabular}

Figure 1: Comparison of serum ALT, AST and ALP activities (mg/dl) in different studied groups: control; G2: Red Bull (5ml/day); G3: Code Red (5ml/day) ; G4: Red Bull (10ml/ day); G5: Code Red (10ml/day). All statistics data were stated as mean \pm SEM using student t-test with significant differences at $\mathrm{p}<0.05, \mathrm{p}<0.001$ and $\mathrm{p}<0.0001$ as indicated by $\left({ }^{*}\right),\left({ }^{* *}\right)$ \&t $\left({ }^{* * *}\right)$ compared to normal control group, respectively.

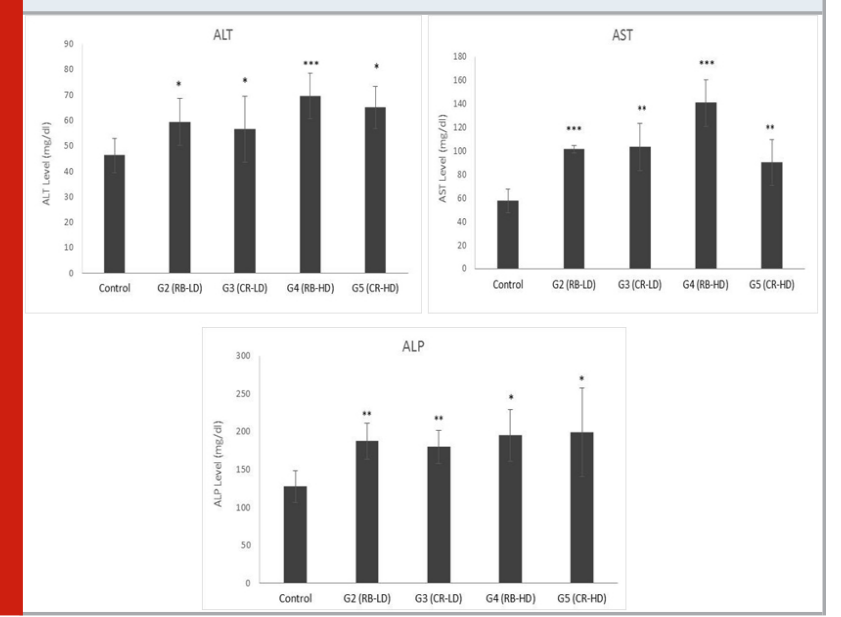

The impacts of EDs on lipid profile as shown in Figure 4excreted a significant lower levels of total lipids, total cholesterol, triacylglycerol, and LDL-cholesterolin experimental animals co-administered lower or higher doses of Red Bull or Code Red (5ml/day or $10 \mathrm{ml} /$ day individually). On other hand, significantly higher HDLcholesterol levels was recorded when administered higher dosages of Code Red in contrast with the control (Figure 4).

Consumption of energy drinks has significant effect $(\mathrm{P} \leq 0.05)$ on serum FAS as well as on ACC activities, significantly higher levels of both enzymes were observed when consumption of EDs as comparable with the
Figure 2: Comparison of serum total protein (TP) and albumin (ALB) levels (mg/dl) in different studied groups, control; G2: Red Bull-low dose (RB-LD, 5ml/day); G3: Code Red-low dose (CR-LD, 5ml/day); G4: Red Bull-high dose (RB-HD, 10ml/day); G5: Code Red-high dose (CR-HD, $10 \mathrm{ml} /$ day). All statistics data were stated as mean \pm SEM using student t-test with significant differences at $\mathrm{p}<$ $0.05, \mathrm{p}<0.001$ and $\mathrm{p}<0.0001$ as indicated by $\left({ }^{*}\right),\left({ }^{* *}\right) \mathrm{Et}$ $\left({ }^{* * *}\right)$ compared to normal control, respectively.

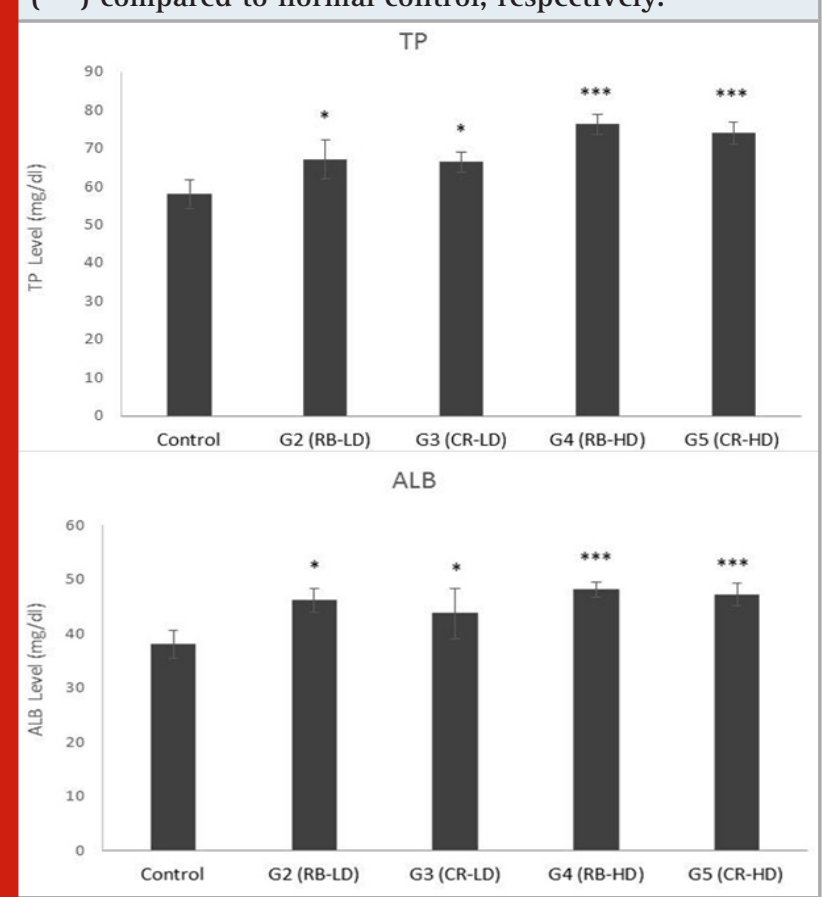

control group. The values of serum FAS and ACC were significantly $(\mathrm{P} \leq 0.05)$ higher in rats administered high doses of energy drinks (RB-HD and CR-HD) than those observed in rats administered low doses of energy drinks ( RB-LD and CR-LD)(Figure 5). 
Figure 3: Comparison of serum totalbilirubin (TBIL) and direct bilirubin (DBIL) levels (Umol/L) in different studied groups, control; G2: Red Bull-low dose (RB-LD, 5ml/day); G3: Code Red-low dose (CR-LD, 5ml/day); G4: Red Bullhigh dose (RB-HD, 10ml/day); G5: Code Red-high dose (CR-HD, 10ml/day). All statistics data were stated as mean \pm SEM using student t-test with significant differences at $\mathrm{p}<0.05, \mathrm{p}<0.001$ and $\mathrm{p}<0.0001$ as indicated by $\left({ }^{*}\right),\left({ }^{* *}\right)$ Et $\left({ }^{* * *}\right)$ compared to normal control, respectively

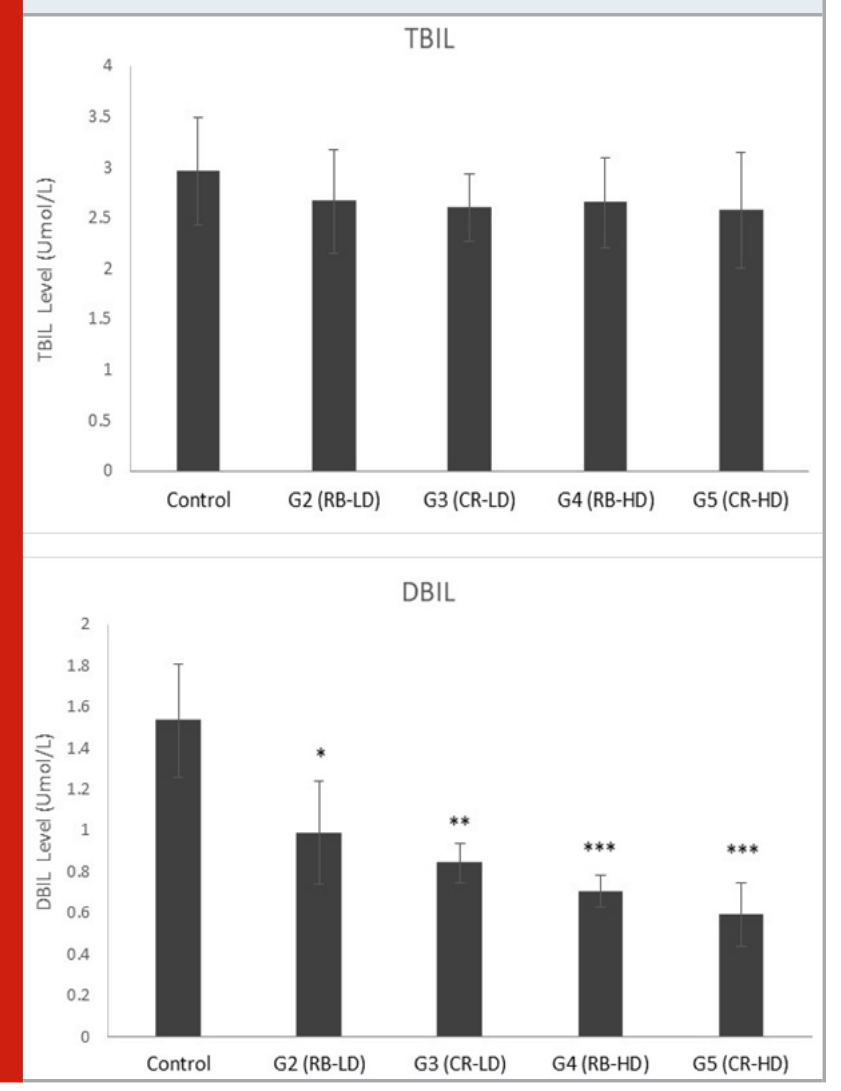

Effect of EDS on Levels of Blood Glucose and Insulin: The results showed that the consumption of EDs led to a significant increase in blood glucose and insulin levels compared to the control group. The results of the present study also indicated that the estimates of blood glucose and insulin were essentially higher (P 0.05) in rats given high doses of RB-HD and CR-HD than those of low doses administered of both types(Figure 6).

\section{DISCUSSION}

In the present research, it was found that Red Bull ${ }^{\circledR}$ and Code Red ${ }^{\circledR}$ have differing effects on liver enzymes and lipid profile. However, both drinks contained increased levels of serum liver markers, which strongly indicates that they may cause a cellular leak and reduce the functional integrity of the hepatocyte membrane (Elsadek et al., 2017, Fathy et al., 2017).The ingredients of energy drinks are absorbed in the intestine, after which they pass through the portal vein to the liver. Thus, higher concentrations of ED ingredients pass through the portal circulation system than the systemic circulation (Pencek
Figure 4: Comparison of serumtotal lipids (TL), total cholesterol (chol), Triglycerides (TG), LDL-Cholesterol and HDL-Cholesterol levels in different studied groups, control; G2: Red Bull-low dose (RB-LD, 5ml/day); G3: Code Redlow dose (CR-LD, 5ml/day); G4: Red Bull-high dose (RBHD, 10ml/day); G5: Code Red-high dose (CR-HD, 10ml/ day). All statistics data were stated as mean \pm SEM using student t-test with significant differences at $\mathrm{p}<0.05, \mathrm{p}$ $<0.001$ and $\mathrm{p}<0.0001$ as indicated by $\left({ }^{*}\right),\left({ }^{* *}\right)$ \&t $\left({ }^{* * *}\right)$ compared to normal control, respectively.

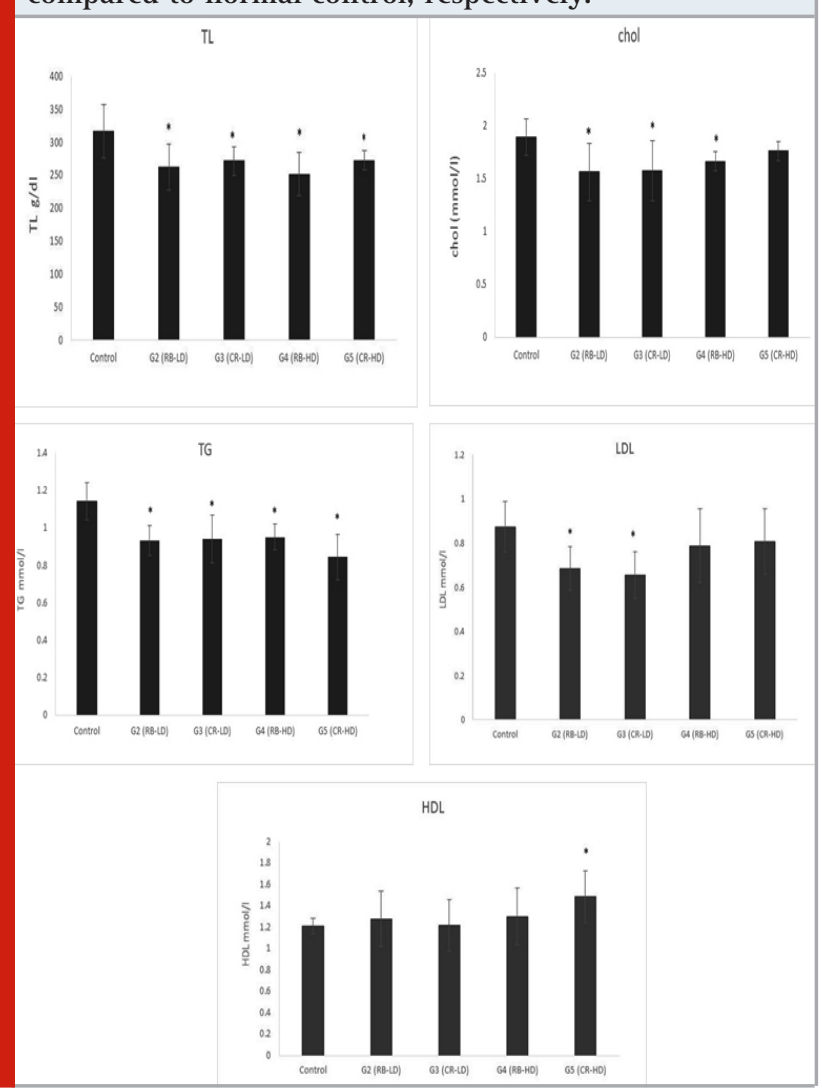

et al., 2004) It is thus likely that the extraction and metabolic conversion of energy drink ingredients take place in the liver.

If liver tissue becomes damaged, it can cause cellular enzymes to spill out into the blood, causing an increase in plasma or serum. This suggests that hepatic injury can result from the consumption of such drinks. Many researchers were in line with those of the present study, namely that increased serum AST, ALT and ALP are produced during long-term energy drink consumption(Kutia et al., 2019, Ugwuja, 2014, Mancy et al., 2017, University et al., 2019). On the other hand, Costa-Valle et al (2018)performed a study in which they singly administered $10 \mathrm{ml} / \mathrm{kg}$ doses of "Red Bull" to rats and found that these enzyme levels were within the reference range. However, the different experimental models used in different studies may explain the variation in results regarding the impacts that energy drinks have on hepatic functions. In other words, research findings may be impacted by the different animals, energy drinks, dose and duration of use employed in each study. 
Niacin(vitamin B3) can cause hepatotoxicity, varying from mild aminotransferase increases to complete hepatic failure(Leung et al., 2018).

Figure 5: Comparison of serumfatty acid synthase(FAS) and acetyl-CoA carboxylase (ACC)activities in different studied groups, control; G2: Red Bull-low dose (RB-LD, 5ml/day); G3: Code Red-low dose (CR-LD, 5ml/day); G4: Red Bull-high dose (RB-HD, 10ml/day); G5: Code Redhigh dose (CR-HD, 10ml/day). All statistics data were stated as mean \pm SEM using student t-test with significant differences at $\mathrm{p}<0.05, \mathrm{p}<0.001$ and $\mathrm{p}<0.0001$ as indicated by $\left({ }^{*}\right),\left({ }^{* *}\right)$ \&t $\left({ }^{* * *}\right)$ compared to normal control, respectively.

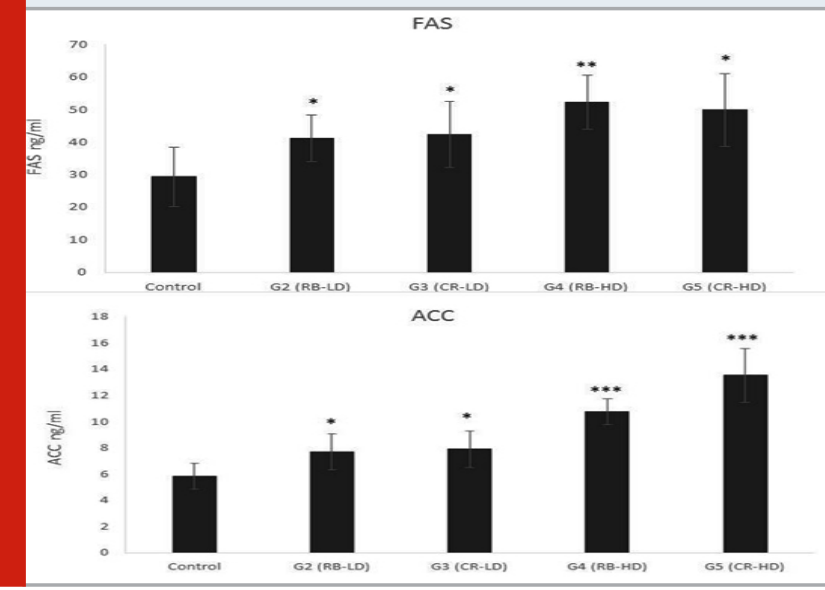

It was revealed in the present study that both types of energy drink reduced plasma total cholesterol, LDL, total lipid and triglycerides. However, these findings contradicted those of other researchers (Ebuehi et al., 2011, Ugwuja, 2014). The reduction in lipid profile largely contrasts the increased bodyweight of the rats after being administered with doses of ED. In the present study, this is understandable because the excess energy consumed is not used, and thus is stored in the body, which ultimately affects body weight. However, this contradicts the findings of other studies which show that combining EDs with exercise or alcohol causes a decrease in body fat (Ballard et al., 2010, Ugwuja, 2014).

What's more, the reduction in cholesterol concentration after consuming both energy drinks may be explained by the increased taurine and/or niacin in the drinks. As both niacin and taurine are used to prevent and treat atherosclerosis, this change may be anticipated (Chen et al., 2012, Julius, 2015). To be more specific, niacin may reduce serum cholesterol and triglycerides whilst simultaneously increasing HDL concentration (Barter, 2011). Furthermore, several studies have investigated the impacts of caffeine (the key ingredient of most energy drinks) on lipid profile and atherogenesis predisposition (Adebayo et al., 2007). Many of these studies have revealed that caffeine consumption significantly alters lipid parameters (Marangon et al., 2012, Nakagawa and Pedrosa, 2013). Moreover, other studies have concluded that most of the observable effects caused by energy
Figure 6: Comparison of serum Glucose (GLU) and Insulin levels in different studied groups, control; G2: Red Bulllow dose (RB-LD, 5ml/day); G3: Code Red-low dose (CRLD, 5ml/day); G4: Red Bull-high dose (RB-HD, 10ml/ day); G5: Code Red-high dose (CR-HD, 10ml/day). All statistics data were stated as mean \pm SEM using student t-test with significant differences at $\mathrm{p}<0.05, \mathrm{p}<0.001$ and $\mathrm{p}<0.0001$ as indicated by $\left({ }^{*}\right),\left({ }^{* *}\right) \mathrm{Ct}\left({ }^{* * *}\right)$ compared to normal control, respectively.

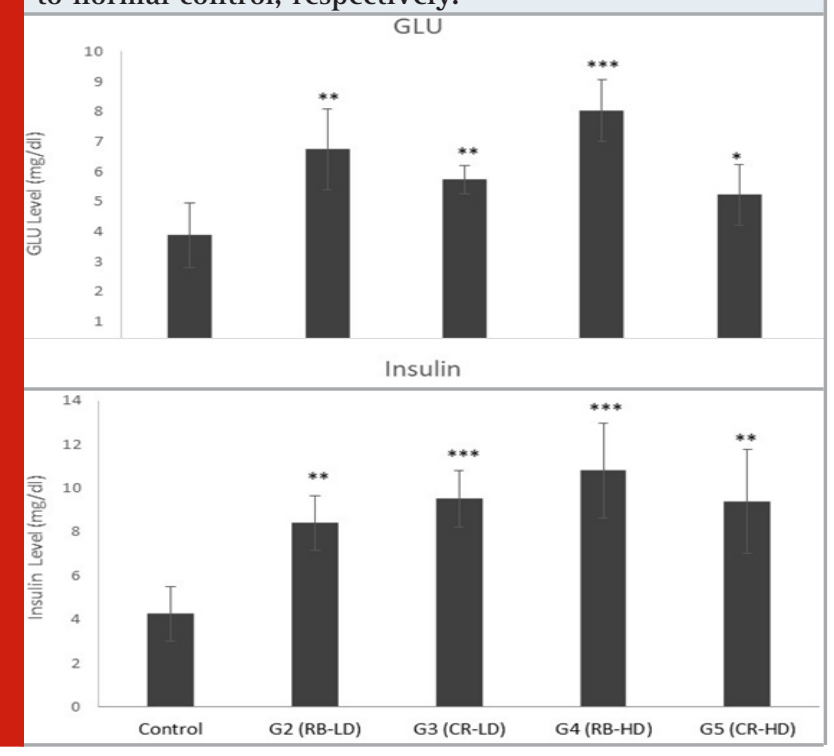

drink consumption are related to caffeine (Kammerer et al., 2014).

These drinks cause major increases in serum fatty acid synthase (FAS) and acetyl CoA ACC. Acetyl CoA carboxylase is a product of the carboxylation process of acetyl CoA, in which malonyl CoA is produced. Additionally, HCO3- and ATP are required in this process. Biotin is a coenzyme here, which covalently binds to lysyl residue produced by the carboxylase. (Harvey, 2011) stressed that long-term consumption of a high-calorie diet causes acetyl CoA carboxylase synthesis to increase, which ultimately increases fatty acid synthesis. In the present work, a reduction in lipid levels was observed. However, this was not reflected in the high activity of both enzymes following the consumption of energy drinks. On the other hand, caffeine could stimulate lipolysis by altering the regulation of FAS and AC, which led to a depletion in TG and cholesterol levels on lipid accumulation in the human liver cell line(Quan et al., 2013).

Serum insulin and glucose levels were found to be much higher in rats who were administered high doses of $\mathrm{RB}$ and low doses of CR in the present study. This is in line with other studies revealed that glucose levels were significantly increased in all energy-drinking human and animal models (Basrai et al., 2019, Macdonald, 2016). Sugar and caffeine are the primary components of energy drinks and they have been found to increase postprandial hyperglycemia in both animals and young 
people(Desouky et al., 2019, Kolnes et al., 2010, Nowak et al., 2018). Moreover, combining niacin with high sugar or carbohydrate content (as is the case with EDs) can significantly impact the metabolism of carbohydrates metabolism and cause diabetes(Zhou et al., 2010).

Funding: This study did not receive any specific grant from funding agencies in the public, commercial, or notfor-profit sectors.

Conflict of Interest: The authors declare that they have no known competing financial interests or personal relationships that could have appeared to influence the work reported in this paper.

\section{REFERENCES}

Adebayo, J. 0., Akinyinka, A. 0., Odewole, G. A. \&t Okwusidi, J. I. (2007) Effect of caffeine on the risk of coronary heart disease- A re-evaluation. Indian J Clin Biochem, 22, 29-32.

Al Yacoub, R., Luczkiewicz, D. \&t Kerr, C. (2020) Acute kidney injury and hepatitis associated with energy drink consumption: a case report. Journal of medical case reports, 14, 23-23.

Alford, C., Cox, H. \&t Wescott, R. (2001) The effects of red bull energy drink on human performance and mood. Amino acids, 21, 139-150.

Bailey, R. L., Saldanha, L. G., Gahche, J. J. \& Dwyer, J. T. (2014) Estimating caffeine intake from energy drinks and dietary supplements in the United States. Nutrition reviews, 72, 9-13.

Ballard, S. L., Wellborn-Kim, J. J. \&t Clauson, K. A. (2010) Effects of commercial energy drink consumption on athletic performance and body composition. Phys Sportsmed, 38, 107-17.

Barter, P. J. (2011) The causes and consequences of low levels of high density lipoproteins in patients with diabetes. Diabetes \&t metabolism journal, 35, 101-106. Basrai, M., Schweinlin, A., Menzel, J., Mielke, H., Weikert, C., Dusemund, B., Putze, K., Watzl, B., Lampen, A. \&t Bischoff, S. C. (2019) Energy Drinks Induce Acute Cardiovascular and Metabolic Changes Pointing to Potential Risks for Young Adults: A Randomized Controlled Trial. J Nutr, 149, 441-450.

Boeck, C. R., Marques, V. B., Valvassori, S. S., Constantino, L. C., Rosa, D. V., Lima, F. F., RomanoSilva, M. A. \&t Quevedo, J. (2009) Early long-term exposure with caffeine induces cross-sensitization to methylphenidate with involvement of DARPP-32 in adulthood of rats. Neurochemistry international, 55, 318-322.

Caine, J. \&t Geracioti, T. (2016) Taurine, energy drinks, and neuroendocrine effects. Cleveland Clinic Journal of Medicine, 83, 895-904.

Chen, W., Guo, J. X. \& Chang, P. (2012) The effect of taurine on cholesterol metabolism. Mol Nutr Food Res, 56, 681-90.

Costa-Valle, M. T., Tonieto, B. D., Altknecht, L., Cunha,
C. D., Fão, N., Cestonaro, L. V., Göethel, G., Garcia, S. C., Leal, M. B., Dallegrave, E. \&t Arbo, M. D. (2018) Energy drink and alcohol combination leads to kidney and liver alterations in rats. Toxicology and Applied Pharmacology, 355, 138-146.

Desouky, A. A., Zaid, A. A., Saify, G. H. E. \&t Noya, D. A. (2019) Ameliorative Effect of Omega-3 on Energy Drinks - Induced Pancreatic Toxicity in Adult Male Albino Rats. the egyptian journal of histology, 42, 324334.

Ebuehi, O. A., Ajayl, O. E., Onyeulor, A. L. \&t Awelimobor, D. (2011) Effects of oral administration of energy drinks on blood chemistry, tissue histology and brain acetylcholine in rabbits. Nig Q J Hosp Med, 21, 2934.

Elitok, A., Öz, F., Panc, C., Sarıkaya, R., Sezikli, S., Pala, Y., Bugan, Ö. S., Ate区, M., Parıldar, H. \& Ayaz, M. B. (2016) Acute effects of Red Bull energy drink on ventricular repolarization in healthy young volunteers: a prospective study. Anatolian journal of cardiology, 15, 919.

Elsadek, B., Mansour, A., Saleem, T., Warnecke, A. Et Kratz, F. (2017) The antitumor activity of a lactosaminated albumin conjugate of doxorubicin in a chemically induced hepatocellular carcinoma rat model compared to sorafenib. Digestive and Liver Disease, 49, 213-222.

Fathy, A. H., Bashandy, M. A., Bashandy, S. A., Mansour, A. M. Et Elsadek, B. (2017) Sequential analysis and staging of a diethylnitrosamine-induced hepatocellular carcinoma in male Wistar albino rat model. Canadian journal of physiology and pharmacology, 95, 14621472.

Glade, M. J. (2010) Caffeine-not just a stimulant. Nutrition, 26, 932-938.

González-Domínguez, R., Mateos, R. M., Lechuga-Sancho, A. M., González-Cortés, J. J., Corrales-Cuevas, M., Rojas-Cots, J. A., Segundo, C. \&t Schwarz, M. (2017) Synergic effects of sugar and caffeine on insulin-mediated metabolomic alterations after an acute consumption of soft drinks. Electrophoresis, 38, 2313-2322.

Grasser, E. K., Yepuri, G., Dulloo, A. G. \& Montani, J.-P. (2014) Cardio-and cerebrovascular responses to the energy drink Red Bull in young adults: a randomized cross-over study. European journal of nutrition, 53, 1561-1571.

Harvey, R. a. P. D. 2011. LippincottE\#39;s illustrated reviews: Biochemistry, Fifth edition. Philadelphia : Wolters Kluwer Health, [2011] ๑2011.

Higgins, J. P., Yarlagadda, S. \&t Yang, B. (2015) Cardiovascular complications of energy drinks. Beverages, 1, 104-126.

Howard, M. A. \&t Marczinski, C. A. (2010) Acute effects of a glucose energy drink on behavioral control. Experimental and clinical psychopharmacology, 18, 553. 
Julius, U. (2015) Niacin as antidyslipidemic drug. Can J Physiol Pharmacol, 93, 1043-54.

Kammerer, M., Jaramillo, J. A., García, A., Calderón, J. C. \& Valbuena, L. H. (2014) Effects of energy drink major bioactive compounds on the performance of young adults in fitness and cognitive tests: a randomized controlled trial. J Int Soc Sports Nutr, 11, 44.

Kolnes, A. J., Ingvaldsen, A., Bolling, A., Stuenæs, J. T., Kreft, M., Zorec, R., Shepherd, P. R. \&t Jensen, J. (2010) Caffeine and theophylline block insulin-stimulated glucose uptake and PKB phosphorylation in rat skeletal muscles. Acta Physiologica, 200, 65-74.

Kutia, S., Kriventsov, M., Moroz, G., Gafarova, E. Et Trofimov, N. (2019) Implications of energy drink consumption for hepatic structural and functional changes: a review. Nutrition \&t Food Science, 50, 937953.

Leung, K., Quezada, M., Chen, Z., Kanel, G. \&t Kaplowitz, N. (2018) Niacin-Induced Anicteric Microvesicular Steatotic Acute Liver Failure. Hepatology communications, 2, 1293-1298.

Macdonald, I. A. (2016) A review of recent evidence relating to sugars, insulin resistance and diabetes. Eur J Nutr, 55, 17-23.

Mancy, W., Alogaiel, D., Hanafi, M. \&t Zakaria, E. (2017) Effects of chronic consumption of energy drinks on liver and kidney of experimental rats. Tropical Journal of Pharmaceutical Research, 16, 2849-2856.

Marangon, A. F. C., Helou, T. \&t Gonzalez, D. V. (2012) Effect of caffeine on lipid profile in ciclism practitioners. Journal of the International Society of Sports Nutrition, 9, P20.

Monnard, C. R., Montani, J.-P. \&t Grasser, E. K. (2016) Cerebro-and cardio-vascular responses to energy drink in young adults: is there a gender effect? Frontiers in physiology, 7, 346.

Nakagawa, P. \&t Pedrosa, M. (2013) Effect of the chronic administration of caffeine on adipose mass and lipid profile of Wistar rats. Acta Scientiarum - Biological Sciences, 35, 293-298.

Nowak, D., Go®li冈ski, M. \& Nowatkowska, K. (2018) The Effect of Acute Consumption of Energy Drinks on Blood
Pressure, Heart Rate and Blood Glucose in the Group of Young Adults. International journal of environmental research and public health, 15, 544.

Pencek, R. R., Battram, D., Shearer, J., James, F. D., Lacy, D. B., Jabbour, K., Williams, P. E., Graham, T. E. Ct Wasserman, D. H. (2004) Portal vein caffeine infusion enhances net hepatic glucose uptake during a glucose load in conscious dogs. The Journal of nutrition, 134, 3042-3046.

Quan, H. Y., Kim, D. Y. \& Chung, S. H. (2013) Caffeine attenuates lipid accumulation via activation of AMPactivated protein kinase signaling pathway in HepG2 cells. BMB reports, 46, 207-212.

Seifert, S. M., Schaechter, J. L., Hershorin, E. R. \&t Lipshultz, S. E. (2011) Health effects of energy drinks on children, adolescents, and young adults. Pediatrics, 127, 511-528.

Souza, D. B., Del Coso, J., Casonatto, J. \&t Polito, M. D. (2017) Acute effects of caffeine-containing energy drinks on physical performance: a systematic review and meta-analysis. European journal of nutrition, 56, 13-27.

Ugwuja, E. (2014) Biochemical effects of energy drinks alone or in combination with alcohol in normal albino rats. Advanced pharmaceutical bulletin, 4, 69-74.

University, F., Nigeria, Y., Gashua, Ekakitie, L. I., Asagba, S. \& Clement, O. (2019) COMBINED AND SEPARATE EFFECTS OF ENERGY DRINK AND ALCOHOL ON BODY WEIGHT AND AMINOTRANSFERASES IN PLASMA AND TISSUES OF WISTER RATS. 27-34.

Vivekanandarajah, A., Ni, S. \&t Waked, A. (2011) Acute hepatitis in a woman following excessive ingestion of an energy drink: a case report. Journal of medical case reports, 5, 1-3.

Wolk, B. J., Ganetsky, M. \&t Babu, K. M. (2012) Toxicity of energy drinks. Current opinion in pediatrics, 24, 243251.

Zhou, S. S., Li, D., Zhou, Y. M., Sun, W. P. \& Liu, Q. G. (2010) B-vitamin consumption and the prevalence of diabetes and obesity among the US adults: population based ecological study. BMC Public Health, 10, 746. 